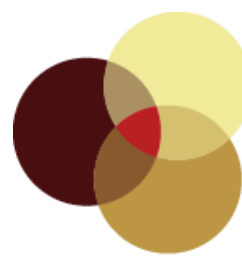

contennporaneity

Vol 1(2011) | ISSN 2155-1162 (online) | DOI 10.5195/contemp.2011.32

http://contemporaneity.pitt.edu

\title{
Contemporaneity in the History of Art
}

\author{
A Clark Workshop 2009, Summaries of Papers and \\ Notes on Discussions
}

Terry Smith

\begin{abstract}
Sponsored by the Clark Institute, Williamstown, and the Getty Research Institute, Los Angeles, the workshop was convened by Terry Smith, and held at the Sterling and Francine Clark Institute, Williamstown, Mass., October 8 and 9, 2009. These notes do not record the exact statements of all participants, neither in the summaries of papers nor notes on discussions; rather, they represent the author's own impressions of the workshop as it unfolded. See also, in this issue of Contemporaneity, Wu Hung's contribution to the workshop.
\end{abstract}

\section{About the Author}

Terry Smith is Andrew W. Mellon Professor of Contemporary Art History and Theory in the Department of the History of Art and Architecture at the University of Pittsburgh. 


\section{Contemporaneity in the History of Art}

\section{A Clark Workshop 2009, Summaries of Papers and Notes on Discussions}

\author{
Terry Smith
}

Sponsored by the Clark Institute, Williamstown, and the Getty Research Institute, Los Angeles, the workshop was convened by Terry Smith, and held at the Sterling and Francine Clark Institute, Williamstown, Mass., October 8 and 9, 2009.

Participants: AA Alexander Alberro; AG Andrea Giunta; AP Andrew Perchuk; AW Anne Wagner; BG Boris Groys; CJ Caroline Jones; DS David Summers; JS Joshua Shannon; KM Keith Moxey; MAH Michael Ann Holly; ML Mark Ledbury; OE Okwui Enwezor; PG Peter Galison; TS Terry Smith; Wu Hung was absent due to illness but sent a paper. Clark Fellows Thierry de Duve and Hollis Clayson also contributed. References, including texts read by the participants prior to the workshop, may be found in the footnotes. Thanks to Nadav Hochman for research assistance. Special thanks to Michael Ann Holly and Thomas Gaeghtens for supporting this project, and to Mark Ledbury and Andrew Perchuk for their work on bringing it into being. These notes do not record the exact statements of all participants, neither in the summaries of papers nor notes on discussions; rather, they represent my own impressions of the workshop as it unfolded. - Terry Smith.

\section{Key Themes}

1. Histories of Contemporary Art. To many, the idea that contemporary art might be subject to historical analysis and interpretation is unthinkable: it seems to be a contradiction in terms (and thus a conceptual error); the proper province of critics, not historians, who should just wait; a practical impossibility given the evident diversity of contemporary art; a mistaken enterprise given contemporary art's radical pluralism; finally, and worst of all, it might, if successful, operate as a constraint on art practice. Recently, however, such objections have been sidelined by actual world historical developments, concomitant changes in art practice during the past forty years, recent shifts in critical theory, and a growing number of attempts by curators and others to apply both historical and art historical perspectives to contemporary art. More broadly, new understandings of "the contemporary" as the multiplicity of ways of being in time are coming into focus.

Is "contemporary" the name of an art historical period that has succeeded modernism, or does "contemporaneity" mean that periodization is past (an anachronism from modernity) both in the general culture and in art? Does it then follow, as many argue, that contemporary art can only be a kind of modernism that has outlived its time? Against this, there is the view that the multiple modernisms and non-modern practices within twentieth century art prefigure the diversity of contemporary art. This implies that shifts from modern to contemporary art occurred in distinct ways in different places, and that tracking these is an urgent art historical task. Looking directly at the present, we might ask whether or not contemporary conditions have reshaped our conception of "the world" (in planetary terms, for example, as worlds-within-the-world), and thus our conception of the currents manifest in global contemporary art? Are the evident interconnections between each region, people, city, even locality in the world today sufficient to enable us to speak of a new, contemporary phase in the "world" history of art?

2. Contemporaneity in the Art of the Past. At the millennial turn, time in art became a much-discussed topic at a number of scholarly fora, not least CIHA 30, London, 2000. If we understand "the contemporary" as pointing to a multiplicity of ways of being in time - in 
particular, to awareness of what is it to be in the present whilst being alert to the "presence" of other kinds of time - it is immediately obvious that this is not just a modern but an ancient concept, and that contemporaneity itself has many histories and histories within the histories of art. The art historical quest unleashed by the idea of contemporaneous temporalities might go all the way back. It pushes us to ask some unexpected questions. To what extent, and how, was awareness of the disjunctions between being and time registered within the symbolic languages that adorned the caves of Africa, marked the deserts and the rocky plateaus of what became Australia, painted in the caves of what became Europe, and created on the plains and islands of what became Asia and the Pacific? In other words, everywhere - and up to the present.

\section{Papers and Discussions}

\section{Session 1 - What is Contemporaneity?}

\section{Terry Smith - Introduction: Contemporaneity and Contemporary Art}

Within the vast proliferation of discourse around contemporary art there is a near-total reluctance - at times, an outright refusal - to engage with key terms, foundational questions, core issues. The range of responses to October's "Questionnaire on 'The Contemporary'" is disappointingly representative of this state of affairs. ${ }^{1}$ The questionnaire is acute in raising the issue of the conjunction of an unthought, almost empty value ("the contemporary") and the elaborate institutional commitment to Contemporary Art. Most responses, regrettably, stayed within this impasse.

If, however, we spotlight the etymology of the word "contemporary" we find much more than mindless up-to-datedness: the Oxford English Dictionary's four definitions bespeak a multiplicity of ways of being in time, and of so existing with others - who may share something of our own temporality but may also live, contemporaneously, in distinct temporalities of their own - and thus also share a sense of the strangeness of being in time now. In the same dictionary, the word "contemporaneity" is defined, simply, as "a contemporaneous state or condition," one that could, of course, occur at any place or time. Yet if we read this term through the richness we now see in the term "contemporary," we recognize its potential to name a broad, worldwide situation, the most definitive characteristic of which would be the experience of multiple ways of being in time with others. Our time, in fact.

Let me gloss the workshop themes summarized above from this perspective. We might take particular contemporaneity to mean the immediacy of difference - in three strong, usually but not necessarily interdependent senses: difference in and of itself, difference to proximate others, and difference to oneself. In his essay, Ian Baucom highlights localizable contemporaneities of this type. ${ }^{2}$ When it comes to art, we would expect to find specific instances of engagement with contemporaneity throughout its history. For example, in What is Contemporary Art? I describe Caravaggio's The Taking of Christ (1602), that I saw in Dublin a few years back, just after it was liberated from a monastery there, in these terms:

\footnotetext{
1 "Questionnaire on 'The Contemporary'," October, no. 130 (Fall 2009), 3-124.

2 Ian Baucom, "Introduction: Atlantic Genealogies," South Atlantic Quarterly 100, no. 1 (Winter 2001), 2 13.
} 
In this painting, contemporaneity is manifest not only in the artist's cladding of the soldiers in seventeenth-century armor while maintaining for Christ, Judas and others costuming imagined as of their ancient time, it is also present in the dazzling centrality of the reflection on the soldier's arm, the attention drawn to the weighty gesture of arrest, the freezing of the rhythms in and out of light and dark that undulate across the painting, the holding of the viewer's eye at just this moment of perception, the grasping of the viewer's soul at the moment of its submission to authoritative possession. Against precursors such as this, Viola's efforts at telling anachronism seem awkwardly contrived. ${ }^{3}$

Georges Didi-Huberman is devoted to readings such as these, taking them to be antichronistic (and thus closer to art's essential spirit). ${ }^{4}$ Less devoted to essences, I take it that there have been many artists who have been alert to multi-chronicity as a quality of the world, especially of world actors (such as Christ) who defy linear or otherwise determined chronicity, and to situations that do so. Another, perhaps better, way of putting this is to say that these actors and these situations have called forth representation time and time again. Let us try to track these occurrences, let them surprise us, let us see what their historical trajectories might have been. A quest, as I say in the second workshop theme, well worthy of our time. Indeed, it may be crucial to the future of art history as a relevant discipline. A danger inherent in this quest is that it could lead us into essentialism, into taking contemporaneity as the only or most definitive thing art does/should do.

Alongside this quest, what might be said of contemporaneity in more general or historical, as distinct from particular, terms? The background readings contain a number of theorizations of world historical trajectories, longue durée tendencies that unfold contemporaneously with each other, sometimes at a sufficient distance for that to be relatively inconsequential, at other times - such as ours - with enormous consequences. Geopolitically, for example, Europe and China from the fourteenth century to the nineteenth, or China vis-à-vis the US and Europe now; Paul Gilroy's tracking of Black Atlantic exchanges; more generally, North/South divides in recent centuries, as in the Three Worlds thesis (to which migrations to the metropolitan centers of the previously colonized have created a dispersed "Fourth World"); similarly, West/East interactions not just on the borders of Europe but more globally, as in Samuel Huntington's "Clash of Civilization" thesis so trenchantly critiqued by Appadurai and others. ${ }^{5}$ These manifest themselves in other spheres, such as the history of thought, as highlighted by Chakrabarty's distinction between History I and History II (with its concomitant obligation to "provincialize Europe"); they also tie to larger forces, as he shows in his recent Critical Inquiry article on historical thinking vis-à-vis ecological consciousness. ${ }^{6}$

3 Terry Smith, What is Contemporary Art? (Chicago: University of Chicago Press, 2009), 202.

${ }^{4}$ Georges Didi-Huberman, Confronting Images: Questioning the Ends of a Certain History of Art (University Park: Pennsylvania State University Press, 2005).

5 Paul Gilroy, The Black Atlantic: Modernity and Double Consciousness (Cambridge, MA: Harvard University Press, 1993); Samuel Huntington, The Clash of Civilizations and the Remaking of World Order (New York: Simon \& Schuster, 1996).

6 Dipesh Chakrabarty, Provincializing Europe: Postcolonial Thought and Historical Difference (Princeton: Princeton University Press, 2000); Dipesh Chakrabarty, "The Climate of History: Four Theses," Critical Inquiry 35, no. 2 (Winter 2009), 197-222. 
One implication of taking these clashing historical big pictures together is that periodization becomes an issue. It could be that our contemporaneity is a condition after periodization, after its possibility - or at least, that we have entered a situation when History exists in the present more and more as a memory of past modes but with little determinative power. At the same time, everyone feels free to invent pasts, speculate futures, although usually at small scales. Jameson reminds us that breaking from the past and prefiguring the future was absolutely central to modernity's identity: it had to periodize, incessantly. ${ }^{7}$ Echoing Ernst Bloch, Harry Hartoonian emphasizes the contemporaneity of the non-contemporaneous in modernity (to him, a phenomenon that is still unfolding, increasingly in this direction). ${ }^{8}$ In his essay mentioned earlier, Baucom calls on us to "map the conjunction of differences." Pouillaude shows this conjunction to be a core concern of contemporary dance. ${ }^{9}$ Everywhere we look, a radical (rooted) contemporaneousness of deep differences.

Giorgio Agamben conceives contemporaneity above all in terms of subjective experience - taking as his key point of reference those intellectuals, poets, artists, scientists who feel most deeply the spirit of the times in their very alienation from it. ${ }^{10}$ This echoes Baudelaire on modernité, and of course Nietzsche's "untimely meditations." For Aravamudan, such readings of the present imply multiple, proliferating futures. ${ }^{11}$ Against these modernist, and pluralistic, views, I see the relationships here as contingent - not the base-superstructure dialectic of classic Marxist theory, not even the revised Raymond Williams one, but rather as Foucaultian structural homologies that occur without predetermination, quasi-accidentally, but occur they do, determine events they do, and those effects stick: history, in this contingent sense, happens, and through this affiliative heterogeneity, shapes our lives. ${ }^{12} \mathrm{~A}$ finite set of forces, I believe, is shaping our contemporaneity:

1. Globalization: drives for hegemony in the face of increasing cultural differentiation, for control of time in the face of the proliferation of distinct, conflicting temporalities, and for continuing exploitation of diminishing natural and virtual resources. Now failing...

2. Accelerated inequity between peoples, classes, and individuals that threatens both the desires for domination entertained by states, ideologies, and religions and the persistent dreams of liberation that continue to inspire individuals and peoples.

3. Immersion in an infoscape (a spectacle society, an image economy, or a regime of representation) that is capable of the instant and thoroughly mediated communication of all information and any image anywhere. It is, at the same time, fissured by the uneasy

\footnotetext{
${ }^{7}$ Fredric Jameson, The Cultural Turn: Selected Writings on the Postmodern, 1983-1998 (London: Verso, 1998); Fredric Jameson, A Singular Modernity: Essay on the Ontology of the Present (London: Verso, 2002).

8 Harry Harootunian, "Remembering the Historical Present," Critical Inquiry 33, no. 3 (Spring 2007), 471 494.

9 Fréderic Pouillaude, "Scéne and Contemporaneity," Tulane Drama Review 51, no. 2 (Summer 2007), 124-135.

${ }^{10}$ Giorgio Agamben, "On Contemporaneity" (lecture given at the European Graduate School, 2007) published in Giorgio Agamben, "What is an Apparatus?" and Other Essays (Stanford: Stanford University Press, 2009), 39-56.

11 Srinivas Aravamudan, "The Return of Anachronism," Modern Language Quarterly 62, no. 4 (December 2001), 331-353.

12 Michel Foucault, The Archaeology of Knowledge (London: Routledge, 2006).
} 
coexistence of highly specialist, closed-knowledge communities, rampant popular fundamentalisms, and open, volatile subjects.

These, in turn, shape art practice in homologous ways, such that three broad currents, each quite different in character, each with internal tendencies, may be discerned, as follows:

1. Official Contemporary Art, visible as art styles and as medium-based practices, has in recent decades taken these forms: Postmodernism, Retro-Sensationalism, and Remodernism. In most of these respects, it continues to be a contemporary elaboration of Modern Art, persisting through the present.

2. The Transnational Turn has drawn artists to engage directly and via indirection with geopolitical forces, ideologies and issues that have been precipitated by the processes of decolonization, the rise of new nationalisms (and their implosion in many cases), the impact of globalization, against which some seek an open internationalism, others a broader cosmopolitanism, within which art may work as a mode of translation between differences. This is a transitional state, obviously; even nations that seem strong in relation to others are undergoing internal transitions of many kinds.

3. Within and beyond these currents, a mostly younger generation of artists deploys strategies to explore their affective experiences of emergent worlds. Four themes recur. World picturing, placemaking and connectivities between them are in constant relationship: location is sought, and dislocation experienced, everywhere and always. Given our new understanding of "the contemporary" as a multiplicity of ways of being in time, and being so with others (of whom we are more aware than ever before, and in unprecedented detail), it is no surprise that asynchronic co-temporality is a recurrent subject. Nor that these artists see themselves as immersed within media, both ubiquitous mass media and mediated communicative systems, while at the same time they seek new kinds of distinctiveness within this envelopment. Circuitry of this kind is a relay between effect and affect.

In my book What is Contemporary Art? I argue that these currents constitute three answers to the question posed by the book's title. While they are in fact contemporary to each other, as a synchronous read of the above outline would show, I am of course implying a diachronic narrative. The first answer, while now dominant, may become residual, and perhaps go into decline, the second is becoming dominant as decolonization (despite many setbacks) continues to unfold around the world, while the artists working in the third current - one that signals world changes that will fill the future - are emergent. In my current project - a textbook on the various shifts from modern to contemporary art that have taken place all over the world in recent decades - I track these currents more thoroughly, especially the second. The framework looks like this contents page of my forthcoming book Contemporary Art: World Currents:

INTRODUCTION: Contemporary Art in Transition: From Late Modern to Now

\section{BECOMING CONTEMPORARY}

\section{Late Modern Art becomes Contemporary}

2. Postmodernism, Retro-Sensationalism and Remodernism

II THE TRANSNATIONAL TURN

1. Russia and (East of) Europe

2. South and Central America, the Caribbean

3. China and East Asia

Contemporaneity: Historical Presence in Visual Culture http://contemporaneity.pitt.edu

Vol 1(2011) | ISSN 2155-1162 (online) | DOI 10.5195/contemp.2011.32 
4. India, South and Southeast Asia

5. Oceania

6. Africa

7. Eastern Mediterranean and Arabian Peninsula

III CONTEMPORARY CONCERNS

1. World Picturing, Making Art Politically

2. Environmentalism, Catastrophe, Planetarity

3. Affects of the Times, Mediated

CONCLUSION: Permanent Transition

This framework is built on a proposition about seeing contemporary art historically, from inside out - it is an art historical hypothesis. I would be very interested in what you think of the methods I am using, and of the hypothesis itself.

Tomorrow, the key question before us will be: Does the distinction between particular vis-à-vis general contemporaneity help us to open out what have become (arguably) increasingly closed histories of past art?

AW: How does Relational Aesthetics relate to "affect/effect" in your schema? ${ }^{13}$

TS: I understand "affect" as the general domain of the affective, but also as the kinds of broad-scale subjectivization brought about via spectacle, and thus take "effect" to indicate the necessity for action between agents independent from, or at least at angles (preferably political ones) to spectacle. So, to me, Relational Aesthetics points to one moment in this shift (during the 1990s) when this was understood and indeed enacted by artists, but that is a memory now.

OE: Yes, look at the trouble Nancy Spector had with the exhibition "theanyspacewhatever" at the Guggenheim. ${ }^{14}$ However successful or not the original situations may have been, the attempt to restage them failed. The question is: how is the contemporary produced? Can it be reproduced? There is a larger issue here about coevality: we may share the same time but not the same space.

AW: We are caught up by the rhetoric of the new. Yet art is now recursive: the contemporary can only be contingent, relational. It is always with us, and always leaving. TS's profile is outmoded because it does not encompass the locally specific. For example, Los Angeles is currently being shattered by economic realities that have been brought about by local, national and world forces. We have to remain alert to the fine grain of the local when we try to map larger forces.

\footnotetext{
13 Nicolas Bourriaud, Relational Aesthetics (Paris: Les Presses du réel, 2002).

14 Nancy Spector, theanyspacewhatever, exhibition catalogue (New York and London: Guggenheim Museum, D.A.P./Distributed Art Publishers, and Thames \& Hudson, 2008).
} 
TS: Indeed we should, and I attempt to do so by treating the art of each region as part of a social historical narrative, as presented by local authors primarily - including the contestations between them. Wu Hung's paper has an excellent, fine-grained account of the interplay between modern and contemporary currents in Chinese art after the Cultural Revolution. It is an exact study of contemporaneity in operation, with many subtle elements. (See Appendix)

AA: We can position small-scale changes against longer-term, perpetual ones when we see them shift together at epochal moments, such as around 1989. These map onto discernable changes in what it is to be a spectator, including a spectator of art.

AG: There are obvious technological changes that transform life for everyone, such as the Internet. The problem is to identify the real modes of mediation.

KM: TS persists with a version of the base/superstructure model as revised by Raymond Williams, yet also claims to be identifying determinations that occur contingently.

TS: In fact, I do both. Williams revised by Foucault, then deconstruction...

AW: Well, we can track the current changes in California to key events of 1974.

AG: As I argue, Argentina entered its current state of crisis in 2001, due to changes in the structures that had prevailed since the 1980s, not because of 9/11.

AP: The key question is what is different/contemporary about these moments? How could one know what would happen?

KM: Surely it comes down to questions of power. Where are these specified in this account?

TS: It is all about power, both as to the premises of the overall picture and in the details.

Question to TS: I am concerned about "world" in the title of your textbook, especially when you treat regions outside the West in the central part, but leave unnamed the fact that you treat the West in the first part. Why is Oceania covered in fewer words than anywhere else?

TS: I want to argue against the idea that transformations in late modern art occurred only in the West, although it is true that those transformations were noted everywhere else. Yet is important to register that many of these transformations were reactions by artists inspired, at least in part, by disgust at what their nations were doing in their role as colonizers, and by admiration for the liberation struggles being undertaken in the Third World. Nevertheless, I will probably add "in Euroamerica" to the title of the first part to make clear the geopolitical spread of the whole conception. As for Oceania relative to the rest of the world, this is the first time that the art of that region will feature at all in such a book. Its relative weight is what it is, not what one might ideally wish it to be. 


\section{Boris Groys - Comrades of Time ${ }^{15}$}

I begin from the title of a film by Alexander Kluge, Attacks of the Present Time Against Other Times. By the latter he meant both the past and the future. It might help us to understand contemporaneity better if we think of how the warring that occurs between different times/periods actually occurs in different times/periods.

Modernity is usually defined as a conflict between the past and the future, the progressive and the reactionary, plus other similar binaries. This permits two perspectives. To the viewpoint that values the past above all, the present is always a time of decline, degeneration, and thus no future is desirable (certainly not more of the same). From a utopian perspective, however, the present is an obstacle to the future; it is not the birthplace of the new, rather it is a slowing down of the coming of the new. For example, in the Soviet Union, with its hope that Communism would come eventually, the present was full of unpleasant delays that had to be overcome. This dream is ironized in the slogan: "Comrades, sleep faster!" Sleeping through the present became a revolutionary duty. ${ }^{16}$

Now, however, we are experiencing a counter-attack against this "sleeping." We find an ever increasing, faster and faster proliferation of histories. Modern perspectives are having trouble with this. For utopians, many futures are too many. For reactionaries, multiplying pasts, all told from present perspectives, is disastrous. Both had assumed one, unified future (if opposite versions of it). Now, however, there is no acceptance of the likelihood of a common future, or of a shared past. Indeed, everyone invents their own history, and thus their individual future. Every author needs to be original. The present thus becomes the production site of historical narratives, more and more of them, overriding past, present, future distinctions.

Some features of contemporary art demonstrate these changes. When we go to a museum it is as if we pass in and out of one screening room after another, with no synchronicity between our spectatorship and the time of the film itself. Being a consumer is a lesser way of understanding; the best way is to be involved in the production, to share in its making, with everyone picking up understanding as they all go along together. Every young artist seeks to invent his or her own heritage.

We are coming to see history as a series of processional presences, as a string of individual moments, each one a present. Participatory art can give us access to such moments: its goal is to produce time. In this sense, we are contemporaries in a new sense, one that comes out if you distinguish between two German words for "contemporary": "zeitlich" means to be in time, or temporary, whereas "zeitgenössiche" - the widely used word for the contemporary as a period - is translatable, literally, as "comrade of time." This translation invites us to work with time, to be its colleague, to help it to be timely.

In all these senses, we may be more contemporary than ever before; more in accord (in time, in tune) with our contemporaneity than past contemporaries have been with their times.

AA: One of the markers of the present is that it seems harder to imagine a future, any future, than it seems to have been even a generation ago. My historical reading tells me that

\footnotetext{
15 Boris Groys, "Comrades of Time", e-flux journal 11 (December 2009). Available online at: http://www.e-flux.com/journal/view/99

16 cf. Sigizmund Krzhizhanovsky, Memories of the Future (New York: New York Review Books, 2009); Sleeper, directed by Woody Allen (USA, 1973).
} 
futures were intensely desired, much thought about, planned for...but now, one hears little talk of futures, just fears.

BG: A recent German government poll among youth about their views of the future found that the thing most desired was that they would retire on a government pension. For them, the State was the future.

AG: I agree that there is a great sense of paralysis at present. It seems hard enough to be able to do anything now, let alone imagine being able to act in the future.

AW: We experience the present mostly through our bodies and minds: through music, at rallies, teaching... It is very specific. The future can be present to us in provisional ways, "as if" it were this or that. Right at the end of Michael Fried's famous "Art and Objecthood" essay, just before he concludes with the quote "presentness is grace," there is an "as if" moment... as if we could experience this work of art in all its fullness, then future grace is possible in the present. ${ }^{17}$ In your Art Bulletin essay, Terry, you misinterpret this, I believe. ${ }^{18}$

KM: Heidegger and Derrida are helpful to us on these questions, especially Derrida's point that to be meaningful the present moment requires a supplement of some kind.

JS: "Moment" is a concept that strikes me as needing some careful thought. The idea of a historical moment is clearly a historians' device, a necessary fiction. We also have to think of such moments spatially: for whom, where in the world, were these events so momentous?

TS: Contemporaneity is precisely a concept that tries to capture the occurrence of events simultaneously and in many, contingently connected places, without presuming that a shared historical unfolding has freeze-framed everything in the same way for everyone involved (see Jim Chandler on England in $1819 ;{ }^{19}$ many of us on 1989, or 2001). Boris is right that we may be more contemporary than before, with less thinking about the future, as Alex says: there is in contemporary experience a thickening of the present, a stretching of it beyond the immediate moment back and forward in time a little, and across world space.

BG: We are perhaps redefining our immediate project in contrast to the utopianism, or the instinctive optimism, of the 1960s. We are seeking a permanent state of presentness. This contrasts with those young Germans who wanted only the security blanket. They are young people with only one wish: to grow old as fast as possible and stay that way for as long as possible.

AP: What this suggests to me is that people are looking for a variety of modes of participation, to be contemporary in different ways.

\section{Okwui Enwezor - Non-Alignment: the Tessellation of Historical Times}

\footnotetext{
17 Michael Fried, "Art and Objecthood" (1967), Art and Objecthood: Essays and Reviews (Chicago: University of Chicago Press, 1998), 148-172.

18 Terry Smith, "The State of Art History: Contemporary Art," Art Bulletin XCII, no.4 (December 2010), 366-383. A manuscript version of this text was distributed to participants prior to the workshop.

19 James Chandler, England in 1819: The Politics of Literary Culture and the Case of Romantic Historicism, (Chicago: University of Chicago Press, 1998).
} 
The crucial question is this: how do we think historically in the present? My goal as a curator is to link what I do in trying to think in this way to the work of the artworks I show, to link the present of those artworks to that of the spectator who will see them, to create in this way a contemporary moment.

We have begun to think about contemporaneity because of the geopolitical interruptions to the previously dominant conceptions of time: above all, the modern - monocultural, monotemporal - view of the contemporary. These breaks occurred in the 1950s, at the Bandung conference that formed the Non-aligned nations, if you want a specific date (1954), and have continued right through the decolonizing process, one that is still going on.

At the 2009 Venice Biennale, Fiona Tan showed her installation DisOrient. Tracking the journeys of Marco Polo through video, photographs, montages and text, through archives as well as through the artist's travels to these places, it was premised on the idea of thinking historically in the present. It shows the archive to be discrepant, not systematic. It is inflected with the artist's own multiple heritages: Indonesian/Dutch, Chinese/Australian. In 1997 she labeled herself a "professional foreigner," as someone who carried a set of usable, unusable, and partly usable identities: Indonesian, postcolonial, etc.

DisOrient was shown in the Dutch Pavilion. In 1993 the German Pavilion showed Naum June Paik and Hans Haacke, artists who had lived for brief periods in Germany, Paik with no German heritage at all. This year British artist Liam Gillick was invited to show in that pavilion. Geopolitical ruptures have dispersed artists all over the world, carrying their archives with them, just as they enter new archives. Tan shows that Marco Polo's journey was a similar experience. DisOrient raises the question of orientation, it challenges Orientalist imaginings, it invites us to "dis-Orientalize."

For example, if you reflect on the recent history of exhibitions such as documenta, it is important to recall the European post-War and Cold War context, and as Serge Guilbaut has shown, the cultural warfare across the Atlantic. But don't forget that the first documenta in 1955 was contemporary with the Bandung conference. We should think of the "tessellation of historical times." In the British Pavilion at Venice this year Steve McQueen showed Giardini, reminding us that we all come from somewhere. This contradicts the postmodern dismissal of tradition, and its love of allegory as a (deliberately anachronistic, ironical) technique for dealing with the coexistence of incommensurability.

BG: Maybe one of the differences between the modern and the contemporary is that there were certain frameworks that were to a degree shared by everybody on the planet, and now there are none. During the 1950s the Cold War hegemony touched everybody in one way or another. Since then, there has been a lack of an identifiable central event. [Both Bush and his opponents tend to see 2001-2008 as the "War on Terror" period.]

OE: But the non-aligned movement was precisely intended to dis-identify with dividing the world on Cold War lines.

AA: Is it not the case that after 1945 the Three Worlds structure was put in place, and that it collapsed in 1989 ?

BG: I see it rather as a split within modernity. From Moscow, the Cold War looked as if it was wracked with tensions.

KM: All of these narratives are invested with many supplements; it is these that destabilize their claims as History.

ML: What is Fiona Tan's vision of contemporaneity? Is it is be in the present of a past project? Or to show misunderstood views of the past as present to us now? 
OE: Tan does not have a central point of departure, because she lives within open archives. In contrast to what Terry calls placemaking she lives within placelessness, a "professional foreigner." Steve McQueen's Giardini - which in the manner of an ethnographic film, tracks the Giardini during the months when the Biennale is not being shown - also exposes the inauthenticity of national pavilions. The point is that we are now all living within the postcolonial constellation.

AW: Is every artist positioned in relation to a specific (national, civilizational, ethnic) cultural archive, or some general one? If there are no cultural limits, then who can speak to which past, any past? For example, do we still ask: can a white person from the US authentically do $x$ ? Would this not proscribe documentary, for example?

OE: I am reminded of Kara Walker being attacked by Betye Saar and others when she won the MacArthur in 1997, when they accused her of feeding "white guilt." [When they meant that she was trashing Black Americans, especially women.] The archive is open to everybody.

Thierry de Duve: I accept your reading of Fiona Tan's work, but am puzzled by her Saint Sebastian. Its treatment of the young women archers performing the Shinto ritual seems to evoke a rather standard set of modern binaries, and be lushly beautiful in a way that the other works are not.

General agreement.

Question to OE: Say more about how curatorship can impact on art history.

OE: Many exhibitions are art historical arguments. For example, most directors of documenta have attempted to reframe prevailing art historical narratives, often by showing artists or tendencies that have been neglected. 1955 aimed to bring West German art contemporary with the US; at documenta 10 Catherine David reminded us of the centrality of Oiticica and Pistoletto...this is true even of Daniel Birnbaum's recent Venice Biennale.

AG: Exhibitions are crucial to rewriting the European and US narrative of modernism. Other nations had their modernities: those stories need to be told.

\section{Anne Wagner - Intersections Between Art History and Contemporaneity: The Everyday}

Cites Henri Lefebvre inviting us to decode the modern world according to the everyday, and Michael Fried's remark that we are all literalists for most of our lives. ${ }^{20}$ Violence is the concealed truth of contemporary experience: how do works of art define this? Primarily through the imagery of bodies, through genre such as portraiture or self-portraiture. Contra Fried, or perhaps with him, art seeks to make interesting the ordinariness it aims to supplant.

20 Henri Lefebvre, Critique of Everyday Life (London: Verso, 2002-2005); Michael Fried, "Art and Objecthood," 168. 
What is involved in representing a figure in the late twentieth/early twenty-first century? Mass culture predominates in defining what we are, but what about the ordinary, the aimlessly unspecial character of everyday life? What resources does it retain?

Dan Graham's Figurative (1965) randomly inserted a sequence of numbers, cashregister style, in a magazine where it appeared between advertisements for tampons and a Warner's push-up brassieres. Dollars and cents are at the core of everything on this page, as Graham's insert makes clear. He ties the advertisements to "the contemporary" through the receipt. The work appears on the front cover of this month's issue (October 2009) of Artforum: another contemporaneity, related of course to his current retrospective at the Whitney Museum.

Timothy Hawkinson's E-motor (2002) is an enlarged mug shot of his upper body with sections of his face printed on plastic parts that are attached via plastic tubes that run to a small motor that is digitally linked to a small television monitor. The tubes and therefore the facial parts are animated by the light emissions of whatever program is being broadcast. The feelings that the spectator takes to be portrayed by the face are generated randomly: they have no causal connection to the emotions that may be being portrayed by the television program. The work seems to embody Marshall McLuhan's principles concerning television as a medium: that it is all surface. Yet, while seeming to portray mechanical detachment, it actually conveys the opposite: a sense of desperate affectiveness.

In the absence of readable style, look, or discernable set of intentions, where do we stand in relation to contemporary conditions? I propose that we should return to the everyday as a source of value. It may be routinized, structured by bureaucracies, and commoditized, but it is also vast, and therefore open to change. It is loaded against women, the working class, employees and the young. Lefebvre said that it was cyclical as well as rational. Can it be the grounds of personhood?

Perhaps we can excavate the literal in art since 1966 as in fact the ground of the everyday. In this sense it occurs in a variety of instances, for example, conceptual photography (Heubler, Ruscha), in Johns' appropriations, etc. Perhaps "presentness" is experienced when art's otherness to life becomes visible to you. (This may be recursive: otherness to everyday life may be this art's way of showing you something important about it.)

AP: Causality in the Hawkinson work seems rather obvious, mechanical even.

Thierry de Duve: Many current artists prefer older mediums, obsolete mechanisms.

KM: This work seems to be an allegory of mediation, one of Terry's main themes, or concerns, of contemporary art.

MAH: Can we consider the saying that history is an ailment only when it feels as full as an egg. We are interpreting "contemporary" as being replete with a multiplicity of temporalities, as simultaneously arresting something and holding it within an existent bundle of times. I wonder what George Kubler and Walter Benjamin would have to say about these questions?

ML: Certainly the everyday discussed by Anne is very different from that understood during the eighteenth century.

AW: A phenomenologist, Lefebvre highlighted the dialectic between one time and another as inhering in people's bodies.

TS: In his essay "A Short History of Photography," Benjamin wrote about a photograph by Hill and Adams of a fishwife, of how she seemed to glance up at the photographer, 
perhaps coquettishly, at which moment her glance, he said, flashed through time to stir his sensibilities. There are many contemporaneities in action here. One of them is a time before people were used to being photographed. ${ }^{21}$

AW: What I take away from that essay is the description of August Sander as the unintentional historian of the present day, labeling his project Antlitz der Zeit (Face of Our Time) a "training manual" for reading the present accurately. Overall, the affect of the real that I am speaking about is a moving target: it is found and must be refound. It is associated with the anxiety of identity, with the fear of its disappearance.

DS: Kubler's time zones might be thought of as histories of everydayness. ${ }^{22}$

\section{Session 2 - Contemporaneity with the West, Other Contemporaneities (1960s, 1989 to Now)}

\section{Alexander Alberro - Periodizing Contemporary Art ${ }^{23}$}

We should take a double optic toward this question, one that is both historical and spatial. Yet we cannot expect widespread homogeneity as in earlier periods, not even a Foucaultian episteme. Instead, a theory of hegemony allows us to acknowledge a certain dominance within which subordinate features may be discerned, it allows totality and difference at the same time. It helps us identify a change in the ways art positions its subjects, a change in artistic agency.

In historical terms we can identify 1989 as a turning point within art, geopolitics, and technology. It is not a seamless transition from the modern to the contemporary, rather a radical break. Indeed, it is the focus on this break, by interpreters, that turns the contemporary into a period.

All of its constituent features have come into place in the past two decades. These include iconographic references to globalization; the rise of global exhibitions organized into spectacles that cannot be taken in fully by any one visitor, which produces an overloaded, vertiginous effect that has changed the nature of spectatorship; technological transformations including installations that have changed the kind of time we spend with works; a shift from analog to digital imagery has led us to assume that all images are manipulated rather than that they are veristic, and that fictive methods are necessary to narrate facts; display has moved from the white cube to the black box, from the video monitor to the wall projection; the image has replaced the object as the central concern of art and its interpretation, thus the rise of Visual Studies; avant-gardism has been reconsidered, relational aesthetics and utopic strategies preferred; in philosophical aesthetics there has been a surprising return of interest in essentialist ideas such as beauty; in art writing the emphasis is now on affect, not the search for meaning, a change with serious consequences for critical theory. All of this is occurring in the context of a spatial shift in world power, and the rise of multiculturalism. Experience is all, but the subject is alienated.

\footnotetext{
21 Walter Benjamin, "Short History of Photography," trans. Phil Patton, Artforum 15, no. 6 (February 1977), 46-51.

22 George Kubler, The Shape of Time: Remarks on the History of Things (New Haven: Yale University Press, 1962).

23 Alberro published a fuller version of this text as his response to the October "Questionnaire on 'The Contemporary'." See October, no. 130 (Fall 2009), 55-60.
} 
The artwork is wide open, the spectator active in new ways. All of these qualities are evident in the work of artists such as Olafur Eliasson and Isaac Julien.

JS: Why not persist with the postmodern/postmodernity framework? How do we distinguish between art historical and broader historical realities?

AA: For my generation, 1989 was what 1968 was for an earlier generation. It signifies changes that go beyond those that led to postmodernity in the 1970s and 1980s. Obviously there are artistic precursors: Barbara Kruger consciously made art for audiences with, in her words, shorter attention spans; what we call "critical" or "resistant postmodernism" is one of the first signs of an emergent contemporary art.

BG: It is important to identify changes in the mediating terms between the art scene and the various social layers. One obvious change is on the level of mass culture and art's role within it. During the Cold War period, on both sides, spectacle came from above, from the more powerful - this is true in the Soviet Union and for Pop Art in the US. Now, with Facebook, etc. on the Internet, design has permeated everyday life; everybody is using selffashioning modes from late modernism; everyone is a global spectator of everyone else. Professional art has to resituate itself in this new context to remain professional.

OE: If we think about exhibitions as descriptive spaces, as a place to unfold a narrative, then we can experience them as chronotopes. 1989 does allow us to think contemporaneity differently. "Magiciens de la terre" was a marker of openness to art from outside Europe and America but it located very different art from distinct parts of the world synchronically, in pairs that matched, somehow, formally or thematically. As Terry and Alex say, Contemporary Art can been seen as congealed, as hegemonic in form. Some curators respond to this; one marker might be that since 1989 there has been a growing tendency in megaexhibitions to deliberately create heterochronological spaces, ones that cannot be grasped within the framework of an overall narrative. For documenta 11, we aimed to be anti-hegemonic, to deterritorialize Kassel time, to confront the historical phenomenon that was documenta with its own limits. Against the idea of "epic time" we presented a density of temporalities that no spectator could master (too many $3 \mathrm{~mm}$ video loops); contrasting the time of the works against the time of the exhibition.

When you say that all biennales are disorienting spectaculars, you have to remember practical issues. Only a few biennales can actually be spectacles: many places simply do not have the money to be more than modest. Another paradox: during the 1990s, much of the financing of the megaexhibitions came from older artworld networks such as small scale governmental agencies (like the Arts Council of Great Britain) or private foundations, not cities, nations, etc.

MAH: How can we connect these ideas with those that animated some of the most interesting modern art history? For example, how is Alex's list of qualities of contemporary art different from the set of categories that Alois Riegl told us were being used by the spectator seeking value in modern art in $1903 ?^{24}$

24 Alois Riegl, The Modern Cult of Monuments: Its Character and Its Origin (Cambridge, MA: MIT Press, 1982). 
Thierry de Duve: I am interested in Alex's remark that 1989 was for him what 1968 was for an older generation - me, for example. Clearly, paradigm shifts do not occur every ten years. Contemporaneity becomes relevant when it is offset by factors with longue durée, such as the anti-aesthetic attitude, which represses affect. Compared to, say, Bruce Nauman's work at the Tate, Eliasson's Weather Project looks like Wagnerian kitsch: installing mirrors would have been enough, but that sun, and then a fog machine, really!

AW: Returning to the idea of hegemony, I wonder how useful it is for us now. For Gramsci, it explained the persuasive power of the fascist nation state in Italy, their influence beyond direct coercion. Fascism worked precisely because it was persuasive. How does this relate to the years after 1989 ? Who is operating the hegemon?

AA: To me, 1989 marks a moment when the imagined community that is the nation state slides into the sand, when globalization emerges to set the agenda, when UN style internationalism begins to fail, when statelessness becomes the norm for millions, etc. Who operates the hegemon? Neoliberalism, multinational corporations, finance capital are the operators.

AW: I think that the idea of hegemony needs further work in this context.

OE: If there were hegemony, would there not be one kind of spectatorship?

TS: There are, on my argument, not one, nor an infinite number, but just three kinds of subjects under formation, and thus three kinds of spectatorship coexisting contemporaneously: those set out on my chart earlier. This gives us profiles of power, as an ensemble of contending elements, not a hegemon ruled by one group, or coalitions, or class, or abstraction (such as "Empire"), nor by these in contention (although, of course, on other levels, they are very much in contention). Confusion might arise from failing to grasp the fact that each of these seeks to be hegemonic, but fails.

\section{Andrea Giunta - Argentina Around 2000: Some Implications}

I am not sure that paradigm changes can be tied to specific dates: they are certainly experienced differently in different parts of the world. For Latin America, 1989 is significant mainly because it meant the sudden cessation of Soviet support for Cuba. In art terms, there does seem to be a worldwide shift from the 1960s through the 1980s when we consider postmodernism, the impact of the Internet, the rise in collaborations between artists and social groups as theorized by Grant Kester and Homi Bhabha. What we might name it I am not sure.

The present tense can be more important at some times rather than others. There are the canons established by MoMA, New York. In textbooks on Modern Art, Contemporary Art is the next style following modernity: "moments" replace "movements." All-inclusive models tend to extend canonicity rather than mobilize archives and activate history. In Argentina the pivotal date was 2000, when it was realized that the social redistributions promised by the elected government would not occur.

During this period artist Magdelena Jitrik was invited to join a community (San Selmo) engaged in urban redevelopment. She produced a design for a do-it-yourself building so that its apertures spelt out the word "Libre." This is a contemporary response, but is also traditional.

Perhaps the generation for whom 1989 was pivotal is so uncertain about the future, and so afraid of a return to the past, that it elects to stay inside this time, the present.

KM: This paper makes it clear that certain stories may work in dominant centers, but will not work in other places. 
AG: Because of its history - particularly the Spanish and Portuguese occupations, then the national liberations - Latin America is not postcolonial in the same way as elsewhere. Many countries see themselves as European.

TS: If we think of the present in a "thickened" sense, we can stretch our synchronic gaze - one that on my model sees three historical currents moving through the present simultaneously, yet a different rates, with different kinds of power, and probably different fates - in a diachronic way, pushing back in time, and forward, in both directions at once as it were. After all, the mapping that I offer covers a forty-year time span up to now, and goes forward. This is the present we are in, thickly.

BG: We must not forget the class factor. Contemporary art looks very different depending on whether you can afford to buy it, and which art you can afford. This gives you a different perspective from when you are contemplating it as a phenomenon from a distance.

OE: And it is important to remember from where one is looking, from which position of cultural power within the still unfolding history of colonialism.

\section{Session 3 - Contemporaneity within the Modern, in the West, Mostly}

\section{Peter Galison - Time in Modern and Contemporary Physics}

If there is one consistent trajectory in physics since the early twentieth century it is that ideas of time have been destabilized again and again. Relativity has been succeeded by multiverses, then these by current ideas that the most basic elements of matter are a state of froth.

At the end of the nineteenth century, it seemed to many physicists that the earth was slowing. Time measurement was changing, against the presumption of choices about time, local times, those of train timetables, etc. Empires imposed their own times as global by locating themselves as centers of worldwide zones (e.g. Greenwich Mean Time). Time itself was measured via simultaneity, as signals exchanged between two clocks, allowing for the time of transmission. This seemed universal, or at least seemed to open the world to being mapped via time measurement: thus the great expeditions, the laying of transmission cables under the oceans, connecting everywhere via telegraph signals. Poincare, speaking in December 1900, could bring together the three major discourses of physics: a philosophy of time, a technology of measurement, and the laws of the electrodynamics of moving bodies. This was paradigmatic: metaphysical issues were physical, too.

Einstein, in contrast, was not at all interested in the actualities of managing an empire, rather in what the world must be if the laws themselves were consistent. Physical issues became metaphysical. It followed that different kinds of time were possible in different states. There was no "universal tic-toc." While Euclid's geometries were true and useful in everyday life, Einstein's higher geometries were necessary at universal levels. General relativity is a theory of the behavior of light in universal time and space; it explains all fields of matter, it presumes that nothing existed before and is untroubled by this. Space-time is a product of pure energy, within which objects move depending on the movement of other objects. Some artists responded to theses ideas. Duchamp read Jouffret's studies of 
geometry of the fourth dimension, ${ }^{25}$ Buckminster Fuller imagined a Time Lock in $1927 .{ }^{26}$ Mendelssohn sought to build Einstein's ideas into the design of his Tower. ${ }^{27}$

Quantum physics demonstrated that aspects of General Relativity did not operate at nanolevels, and thus a unified theory of matter was impossible. By recognizing the existence of many dimensions, perhaps infinities, string theory attempts to bring together General Relativity and the theory of matter. Artists such as Matthew Ritchie illustrate this effort in works such as M Theory (2000) and Yes/No (2004). ${ }^{28}$

Recently, physicists have attempted to rethink the larger "landscape" on which matter itself is being conceived, using concepts such as "event horizon." There is a division of opinion emerging between "landscapists," who allow that matter might exist in a limited number, say 5 or 6 , of forms, incommensurable but connected, and "anti-landscapists," many from Stanford, who posit the existence of 10 to 1,000 , perhaps an infinite number of forms of matter, all realized in a non-concatenated universe, one that is self-replicating, inflationary. Can these two views be reconciled? Do they have to be matched?

The most recent idea in this long history of destabilizations is that space-time might not be a fundamental entity at all, that it might be in constant mutation, like the frothy mix that constitutes a bubble bath, an incessantly mutating manifold. Froth seems to be replacing strings as the theory able to encompass most of what we might know about matter. [If matter is still what is being explained by physics.]

How these changes relate to those occurring in culture in general and art in particular, I leave to you.

CJ: What about Heisenberg's theory that matter cannot be measured exactly due to the "observer effect": the impact of the observation on the phenomenon, of both the recording devices and the consciousness of the observer? ${ }^{29}$

PG: Yes, that is part of quantum theory, of course, but that theory still permits us to predict the behavior of matter at nanolevels and to do useful, even mechanical-seeming, things at that level. This is less a matter of subjective infusion; it is more that the universe splits whenever change occurs - we see it one way or another. This implies an ontological profligacy, the existence of multitudes.

MAH: Are you describing the situation in the philosophy of science or in hard science itself? Why bother unifying space and time? Why not maintain the contradiction between General Relativity and theories of matter?

25 Esprit Jouffret, Traité élémentaire de géométrie à 4 dimensions et introduction à la géométrie à $n$ dimensions and Mélanges de géométrie à 4 dimensions (Paris: J. Gabay, 2003).

26 Richard Buckminster Fuller, 4D Time Lock (Albuquerque: Biotechnic Press, 1972).

27 Klaus Hentschel, The Einstein Tower: an Intertexture of Dynamic Construction, Relativity Theory, and Astronomy (Stanford: Stanford University Press, 1997).

28 See online at: http://www. matthewritchie.com/

29 Werner Heisenberg "Über den anschaulichen Inhalt der quantentheoretischen Kinematik und Mechanik," Zeitschrift für Physik 43 (1927), 172-198. English translation: J. A. Wheeler and H. Zurek, Quantum Theory and Measurement (Princeton: Princeton University Press, 1983), 62-84; Werner Heisenberg, The Actual Content of Quantum Theoretical Kinematics and Mechanics (Washington, D.C.: National Aeronautics and Space Administration, 1983). 
PG: String theory was meant to be an answer to such questions, resolvable at the level of matter, but the problem was that it proposed reconciliations at levels so small or so distant that they could not be measured. No experiments could check them. Mathematicians have always dreamed of a unified theory. Many now say, no, there are ten thousand theories, maybe more.

TS: Have you sketched out for us the entire landscape of thinking about these questions, both in its institutional forms and in its accounts of matter? Is possible to distinguish a contemporary as distinct from a modern physics?

PG: In the continual destabilization of ideas of time, space, matter, etc. there has been a kind of continuity, however disrupted. At the institutional and intellectual history level the current split between landscapists and anti-landscapists is nonetheless a split within a broadly shared approach, however untheorized at its outer edges. If we had to distinguish a new kind of physics, maybe a new period in physics, I would say that it involves a stepping away from ontological claims. The key question, now, is not "what is the world?" It is "what can we make?" Physics is much more oriented toward engineering, to any kind of science that can be used for the specified purpose, no matters its origins. So there is a hybridized science accompanied by indifference towards ontology. Certainly this outlook dominates university-based research.

In nanoscience the distinction between presentation and representation is being overridden, becoming redundant (to take up a theme treated in the last chapter of the Objectivity book). ${ }^{30}$ At that level it is not a matter of identifying something then working out how to represent it in order to work with it or on it. You just work with it and it changes to do the job required, or, if it does not you modify what you are doing until it does.

BG: I am reminded of Heidegger's comment that science is, after all, a technique, and therefore, like a religion, it cannot think.

PG: Science is based in the ancient practices known then as techné: it still moves back and forth between systems of the sensory, of representation, and of actual existence. Science and conscience cannot be separated; there is no "day pass" from the rest of the world.

Hollis Clayson: How do these considerations relate to recent changes in the biological sciences? I have read that they have become more specialized - into focus on cells, or biogeographics, or bioinformatics, for example - with no one working on the full organism, on "animals."

Question to PG: Could we go back to the question: Is there a contemporary science that may be distinguished from modern science?

PG: Certainly there is no longer a fixed sense of what counts as arising from the history of science. Scientists today feel less constrained by it. From an institutional point of view you could say that the Cold War had the effect of freezing in place certain research structures, above all around university-based, discipline-oriented research. Since the late 1980s, however, this has diversified, with some major private initiatives (e.g. the genome projects).

Lorraine Daston and Peter Galison, Objectivity (New York: Zone Books, 2007). 
Science has, as I said, become more technique focused; there are multiple connections but there is no longer a driving center. As for basic physics, it has changed radically and is seen differently, both inside and outside the profession, thus the froth concept.

TS: Great! Contemporaneity everywhere!

\section{Caroline Jones - Blind Epistemology in Confrontation with Contemporaneity}

A paradox of the current situation is that many artists are very involved with history while at the same time a majority of art historians feel themselves in crisis as to how to deal with the contemporary. Sarat Maharaj recently concluded that art history has nothing more to offer, and that curators have made the contemporary into a counter-discourse. ${ }^{31}$ Irit Rogoff argues that the object of Visual Cultural Studies should be to produce and defend spheres of activity in which contemporaneity can enact itself.

Art is always con-tempo, that is, timeless, an opening out to a perpetual and ever shifting present. What counts as "now"? For Hartoonian, it is 1969-2009. These ideas are explored very well in Ben Rubin and Mark Hansen's Moveable Type (2007), an installation in the lobby of the Times building in New York featuring 560 small-screen panels that project texts from the day's news stories.

In some art discourse, "experience" is the key value: it seem to be envisaged as a pure present, without words or ideas being made palpable, just experienced - for example, the Utopia Station section of the 2005 Venice Biennale, or in Olafur Eliasson's environments. To me, the "contemporary" is a moving target, changing constantly, but always specific to its moments. I agree entirely that we should write histories of these changes. In my current project I begin from a narrative produced in 1851, a visit to the International Exhibition supposedly by a blind man: the conceit being, of course, that, undistracted by the dazzle, he was able to "see" the exhibits for what they really were. Today, the contemporary artist has been delegated a similar role, as someone so open to present experience, so able to absorb it unfiltered, that she is uniquely positioned to be the most qualified producer of knowledge about the present - a blind epistemologist. The difference being that she operates with her eyes wide open to the overwhelming visuality of contemporaneity.

Plato's cave allegory is a subject of great interest to contemporary artists (for example, Mike Kelley). The relationship between vision and blindness, truth and deception is at the core of Western thinking about the operations of thought itself. Socrates is just one of many mediators between these states. In the engraving by Jan Saenredam after Cornelius Cornelisz, The Cave of Plato, 1604 (British Museum), the professoriate is shown as the mediator. For Descartes, and Diderot, the blind man has sensations more intense than the sighted, that is, he feels the world more. If a blind philosopher feels the surface of a globe: is he experiencing the world as a picture?

During the twentieth century, blindness comes into fruitful conjunction with the technological sublime. Duchamp's Blind Man (1917) through to Mariko Mori's Wave UFO to the whole genre of relational art, art that is increasingly embedded in the "experience economy." These relationships are questioned by some artists, such as Kutlug Ataman in his Strange Spaces (2009), and Javez Tellier's 2008 video in which people with distinctly marked

\footnotetext{
31 Maharaj made this comment during the 2009 Bergen Biennale conference. See Elena Filipovic, Marieke van Hal, and Solveig Øvstebø, eds., The Biennial Reader: An Anthology on Large-Scale Perennial Exhibitions of Contemporary Art (Ostfildern-Ruit and Bergen: Hatje Cantz \& Bergen Kunsthall, 2010).
} 
race, class, and gender differences describe an elephant. The contest here is between generalized knowledge and the ethics of the partial view.

DS: In his Optics, Descartes uses the metaphor of a blind man's sticks to conjure the operations of human sight. ${ }^{32}$ But we have moved from such indexical knowing into much more complex, variable domains of visual understanding, through movies, mass media, the Internet, etc.

CS: An interplay between the experience of objects and the virtuality of imagery experienced through video and digital screening is a core concern of contemporary art. Of course, it goes both ways: many artists are fascinated with the materiality of anachronistic apparatus (e.g. Tacita Dean, Eliasson). Analogue projectors come to seem like sculptures in some installations.

AA: Sound, and smell, "taste" in a more literal sense - these are becoming more important, although few writers recognize this. It is a legacy of the early 1960s in Latin America, of Lygia Pape, Lygia Clark, Oiticica, and it links to New York art via projects such as Matta-Clark's Food. ${ }^{33}$

CS: Gesammtkunstwerken, but at a smaller, more intimate scale.

BG: Merleau-Ponty's epistemology is, I think, relevant to Caroline's project. And we should not forget the last implication of the cave allegory: when the philosopher returns to the cave, enlightened and ready to lead others out, they will kill him.

KM: Contemporaneity seems to privilege the partial view, to value heterochronicity, the present in presentation. It also seems to include "escapes" from time, or at least linear historicization, as in the multiverses Peter spoke of: these are other, beyond human being.

CJ: In Xu Bing's Book from the Sky something like this is thematized: the universe is presented as a book that writes itself, as a total environment, the ultimate Enlightenment. Yet, this world is indecipherable, because the characters are fake - in fact, it is meaningless.

OE: In South Africa at around the same time (1998) Willem Boshoff began his ongoing series The Blind Alphabet, consisting of wooden "signs," icons in Braille, readable to the touch of a blind visitor, but otherwise unreadable. There are obvious political dimensions to these works, in their contexts.

MAH: What are the implications for art historical method of these revisions of our sense of temporality? With so many temporalities coexisting, and more appearing every day, is the only method left to us a kind of let's "cut the salami" and look at what is in the slice?

TS: That would be to do a synchronic read, to see the present as a frozen array of elements that are coherent only because they have been sliced. It risks mistaking observation for reality. I think, instead, we have all been highlighting certain forces,

\footnotetext{
32 René Descartes, Discourse on Method, Optics, Geometry, and Meteorology (Indianapolis and Cambridge: Hackett, 2001).

33 Catherine Morris, Food: Gordon Matta-Clark (Köln and Manchester: Walter König and Cornerhouse, 2000).
} 
tendencies, trajectories that are unfolding through a thickened, extended present, one that can also be read diachronically. Alex outlined a post-1989 hegemon; Anne put her money on the depths of everyday life and its resistance to spectacularization; Okwui has defined a "postcolonial constellation" as the main figure. I have outlined a paired, three part schema, for both contemporaneity in general and contemporary art in particular.

AW: We will keep on debating these questions, I am sure, but for now I just wanted to draw attention to some further aspects of Duchamp's work relating to vision. The whole trajectory of his enterprise leads toward the sighted viewer, the enabled spectator. After all, his "anemic cinema" attacked the seductions of its day. His business card described him as a "precision occulist." The interplay between subjectivization and criticality in his work remains relevant.

\section{Joshua Shannon - The Contemporary Art Historian}

In 2007 Maurizio Nannucci spelt out in neon a statement across the façade of the Altes Museum, Berlin: ALL ART HAS BEEN CONTEMPORARY. This is true now, but has not been equally true of all times. What distinguishes the contemporaneity of recent art, compared to that of other times and places? Perhaps it is that it is more difficult to think present contemporaneity than it was before?

The Society of Contemporary Art Historians (which you can join just by sending me an email) and the Contemporary Art Think Tank do not have methodological agendas - indeed, you could say that they have non-methodological agendas. They are responses to the enormous interest in contemporary art among art historians: the CAA lists now regularly feature twice as many job searches in this very new field than for two previous hot areas nineteenth century and American art - combined.

"Contemporary" means different things when it is deployed in art criticism, art theory, art history, and art practice. To me, history is the key: through intense critical examination of contemporary art we can learn much about the history of recent decades.

Is exploring the history of artmaking the same as looking for its "contemporaneity"?

For the October critics/historians, history is a longue durée, an epistemic phenomenon conceived in Foucaultian, Adornesque terms. They favor an economic political totality, and view possible subjectivities are shaped by these conditions. They pay less attention to the details, the locations, the specifics of intense particularity that one finds in archives. We need, I believe, to get out from under the model (handed to us by several October writers) that good art must be above all "critical," asking instead that it be, above all, deeply and revealingly "representational" of its age. The aim, then, is to learn about a period from art, rather than ask whether the works have political agency in themselves. Critics and historians need to show us the complexity of contemporaneity.

We should always assume the presence of contemporaneous cultures, some echoes of past cultures, others greatly changed, all of them revolutionary, all in constant interaction. Today, because of global connectivity, contemporaneity is no longer incidental, inconsequential. Consider the contemporaneity of Rubens to his time, compared to that of, say, Nikki S. Lee today: in all cases it is a matter of their coordinates in relation to power.

Is there anything relatively coherent that we can call "contemporary art"? Two fissures question this possibility, one temporal, the other geographic. If we compare art from the 1950s and 1960s with that since 1989 it is clear that each requires a different historicization - that some kind of at least informal break occurred. Similarly, the spread of attention from Paris and New York to Los Angeles and elsewhere across the same period shows that contemporary art is now more "inclusive." "World Art Now" is tenable as a single field; there is a widespread sense of belonging to a shared place and time, however internally contested. Yet the idea of world contemporary art, crucial and indispensable as it is, has two endemic 
problems: (a) what dates are "contemporary"? (this word is a convenient fiction used to refer to the recent past), and (b) is date now more important to art making than place (i.e. is art now more contemporary than it is Chinese, American, etc.)? That may often be the case, but we should never assume so. This temporal shift and geographic spread raises some interesting conundrums: for example, is Jasper Johns a contemporary artist?

Two imperatives come into view. We must overcome the provincialism of EuroAmerica by locating contemporary art everywhere and at the same time. Yet also acknowledge that each geographic region has priority, at least to itself. This leaves us with a hybrid, and with the problem of articulating "the contemporary" when we move from the specific to the general. The move here does not create a new periodization, rather a signal that the work in question belongs to the recent past, a placeholder within the present, a trial balloon, with future capacities, possibly...

KM: How do we decide that one contemporary artist is more contemporary than another? Especially when we acknowledge, as Terry does, non-synchronous contemporaneities.

CJ: Another problem here, in the expansion of the field, is the danger of replicating the issues around area studies: can we speak of "the art of the Middle East" without being Orientalist? I do not think so.

PG: As well, there is a political history to historical thinking that needs to be taken into account. Think of the chain of modes of historical inquiry that dominated the practice for centuries, only to fall away: the classical historians; diplomatic history; Marxism - all, in their ways, were objectivist objections to presentism.

OE: We need to be aware of the "pothole effect." Daniel Birnbaum was criticized for including some less than blue-chip works in the 2009 Venice Biennale: but why not a biennale of terrible works from everywhere? That would shake things up.

What Terry calls "Official Contemporary Art" I see as Westernism plus those artists from elsewhere whose work can be "seen" or recognized as art by viewers in the West or elsewhere with this perspective. But there is a whole other field of encounters between artists and their localities: Kinshasha "popular painting," for example, takes two forms: Western type and local type - you can find, or commission, either one. The point here is that contiguous cultural spaces like these coexist all over the world. They can connect, or not, depending on preferences, circumstances, etc. This is another important way in which contemporary art relates to contemporaneity. In my essay in the Altermodern catalog I speak about an "off-center" condition, and cite the work of curators such as Patrick Flores who track these kinds of relationships in places such as the Philippines and Malaysia. ${ }^{34}$ There is no single, general picture of contemporary art.

\section{David Summers - Real Spaces and Contemporary Art}

Let me begin with a comment on periods, and art historical periodization. Gombrich reminded us that classicism defined itself against barbarism. It may be that contemporary art will define itself not so much in relation to contemporaneity but via exclusion from it.

34 Okwui Enwezor, "Modernity and Postcolonial Ambivalence," Altermodern: Tate Triennial, ed. Nicolas Bourriaud (London: Tate Publishing, 2009), 27-40. 
Other tendencies have worked in different ways: we can read the Baroque as a mode that neutralized critical judgment, and defended classicism from contemporary threats. The best way of going forward is by constantly adjusting our aesthetic attitude to works of art.

Taking art history as a whole, it is evident than an administrative taxonomy survives, and seems essential to the discipline (it has changed Renaissance to Early Modern, for example). What are we to make of the fact that the Italian Renaissance and the highpoints of Aztec culture are parallel in time, that 1521 marks the incidental contemporaneity of Europe and the Americas, the Renaissance and the Age of European Expansion? The "New Spain" developed a local Spanish classicism; art in Mexico has a revolutionary past, yet we use blunt tools to examine Mesoamerican art. If we draw on anthropology and archaeology we can introduce intercultural interaction into art historical methodology. This was my goal in Real Spaces. ${ }^{35}$

We need to rethink what art is, not least to place Western art within world art traditions. Western art production assumes mental images, then an idea of work - assumptions not shared in the East. The key terms are not visual but spatial, if we want foundational, universal bases. Human sociality is at the core of architecture, images, etc. Social spaces last longer than their usages.

Contemporary art does have a distinctive set of real spaces: museums, biennales, new media, art schools, etc. It also seems tied to a progressive political program centered on human rights.

Museums offer new conditions for art, they become more and more important in modern and contemporary architecture. They have made us more aware of the spaces of display than ever before. They are also the sites of institutional critique.

In his book, Terry cites Heiner Friedrich on the immediate experience of art having the potential to enable a transcendence of history. ${ }^{36}$ Yet Pueblo Indians were very conscious of building structures that would be there long after their own lives, and after the lives of generations to come. Art has never been one thing: historical particularity is not the same as aesthetic particularity. Place and time should be respected in both. Every culture has a chronology unique to itself: art historians should be alert to each one, discern their uniqueness. "International art" is a misnomer: people within each culture have lien on their traditions. These values give us a basis to think about an art history respectful of rights and of specificities.

JS: Since Stella's black paintings, there has been a progressive literalization of abstraction in art: from Judd's specific objects that require particular observer behavior, to the current prioritization of the viewer/spectator over the object. I am trying to think how your outline relates to changes such as these.

AW: There are many implications in such questions. Another one is: what kind of temporality does an observer have in relation to every artwork after the invention of photography? Is it, as Benjamin suggests, no longer auratic? More generally on David's proposition: of course we should endeavor to apprehend and respect difference, right up to the limits of our own perception of it.

\footnotetext{
35 David Summers, Real Spaces: World Art History and the Rise of Western Modernism (London; New York: Phaidon Press, 2003).

36 Terry Smith, What is Contemporary Art?, 38-39.
} 
DS: Respect is the foundation of recognizing rights: obviously, you cannot have one without the other. The great pre-Columbian sculpture Coatlicue embodies values and beliefs - re sacrifice, for example - that we would find abhorrent, but we respect their embodiment in this work.

AW: Looking at a work such as this in a museum enables us to ask: how did this set of values come into existence, why did they find such powerful form in this work? The museum could come to be a place where intercultural rights could come to be identified and respected — indeed, many museums are precisely such places.

Returning briefly to Benjamin on the decline of the aura: he was registering its decline in a Europe subject to rising mechanical reproductive modes themselves brought about by the industrial revolution; he did not speak about its decline in the rest of the world. Indeed, he did not address the situation outside Europe (and presumably the US). Art historians, by contrast, should explore the pasts that were specific to each part of the world, and bring them into the present in ways appropriate to the present needs of that culture.

MAH: This raises, again, the question of anachronism. Didi-Huberman has reminded us of the power of images to be alive in every situation. Before each work of art we have a shorter life span. Indeed, we have a number of ways of relating to each work historically: Riegl made important distinctions between "historical value" and "eye" or "present value."

DS: I am not keen on periods, either as used by historians or art historians. Usually, they are evidence of cultural blindness. Art's history reveals, mostly, continuities over very long stretches of time: for example, the optical tradition in the West. Under some culturally specific conditions, substitutions can be made: for example, Western modernism is a real, and recent, break in the history of world art.

CJ: There are many events occurring now that have a periodizing character to them, and some art addresses this question directly. Some feel that the more confusion there exists on this front the better.

Thierry de Duve: Periods are often proposed by those living through them, and by those seen later to have lived through one (that is, period status is often assigned retrospectively). Both impulses always compete, and are obvious today.

\section{Keith Moxey - Do We Need Another Renaissance?}

Since Burkhardt the idea of the Renaissance as a period of great art has been central to the very idea of the history of art. ${ }^{37}$ Are we reaching a point at which Contemporary Art however defined, or left undefined - might be replacing the Renaissance as this core object? Let me tackle this question in five steps.

1. Burkhardt placed the Renaissance at the birth of art's embrace of modernity, that is, his own time. This was the first grand schema linking art to broad historical progress. For Panofsky, the Renaissance overcame the miseries of the Middle Ages, and released their potentialities. ${ }^{38}$ Conceptions of the Renaissance as continually rebirthing, or modernizing,

37 Jacob Burckhardt, The Civilization of the Renaissance in Italy (New York: Harper \& Row, 1958).

38 Erwin Panofsky, Renaissance and Renascences in Western Art (Copenhagen: Russak, 1960). 
itself prevailed until the $1960 \mathrm{~s} / 70 \mathrm{~s}$. Since then this great narrative has been subject to a number of critiques: postmodern, postcolonial, poststructuralist. These have proved devastating. We are left with what Didi-Huberman calls "the anachronism of images."39

2. Contemporary Art: its recent triumph challenges modernism, but it also challenges this great art historical narrative, and may be the final nail in the coffin of this grand historical schema. If modernism remains crucial to the contemporary as the main point of opposition, art before modern art (as Hans Belting refers to $i{ }^{40}$ ) has all but disappeared from sight, and the idea of the Renaissance is falling way. The art of the past is seen as being defined by continuity and stasis, modern art by change and breakage. Postmodernism is seen as too 1980s, but perhaps this is a sign that it is still too hot to handle? Jameson's argument for postmodernity remains influential, even though he reduced it to late capitalism.

3. Contemporaneity: is it a period, or the end of time-based understandings of the world? There is a lot of apocalyptic thinking around: End of Art, the degradations of the Cultural Industry, etc. Marc Augé speaks of "asynchronic slices of time" coexisting; ${ }^{41}$ Nicolas Bourriaud of the "Altermodern" as a moment, not a period, precisely in order to avoid teleology. ${ }^{42}$ Yet there is an element of incoherence in the spaces between the specificities of "other" cultures. And there are commonalities, common kinds of denomination, such as the world time system. Is the concept of contemporaneity haunted by the concept of modernity? Does the latter project developmentalism as an eternal present?

4. There are different stories within heterochronicity: how are these to be related to each other? Peter Galison spoke of landscapists and anti-landscapists among contemporary theorists of physics. Yet even between incommensurable worlds, universes, there are relationships of power: dominant stories repress others. Translation is the task in this situation.

5. This, too, will pass. As George Kubler remarked, we see light after it has traveled toward us for millennia. ${ }^{43}$

Thierry de Duve: Our conceptions of artistic modernity need to be radically revised, rescued from narrow modernism. It has always been more complex than having a teleological conviction. Baudelaire's thinking, for example, was far from teleological; it was recursive, ironic, always doubled. Nineteenth century discourse was much concerned with "the arrow of time." The second law of thermodynamics: can it be averted? The anxieties of the multitudes exist in tension with Hegel's world historical time machine driven by Absolute Spirit: perhaps his thinking was a response to anxiety about multitudes.

To me, the challenge is to produce a radically non-teleological art history. I mean "nonteleological" in the Darwinian sense: that evolution is a complex array of determinative effects that occur, and can be observed to do so, but a unified goal is not part of the process. Intentions, and small-scale purpose, can be seen, but no overall end is in sight. For example, to see Manet without using a Greenbergian optic is to see him very differently; perhaps,

\footnotetext{
39 Georges Didi-Huberman, Devant le temps: histoire de l'art et anachronisme des images (Paris: Editions de Minuit, 2000).

40 Hans Belting, Art History after Modernism (Chicago: University of Chicago Press, 2003).

41 Marc Augé, Non-Places: Introduction to an Anthropology of Supermodernity (London: Verso, 1995).

42 Nicolas Bourriaud, ed., Altermodern: Tate Triennial (London: Tate Publishing, 2009).

43 George Kubler, The Shape of Time: Remarks on the History of Things.
} 
even, as an artist for whom the Renaissance remained important. More generally, art history needs to tell the stories of its many modernities, and do so differently.

PG: If I could comment on your analogy to Darwin's theory of evolution. It is certain that the general theory of entropy allows for, in fact requires, local changes within its overall tendency. There are, of course, other general theories out there: cyclic universes, multiple universes, each contemporary to others but changing differently in relation to each other. The implication for thinking about modernity is that there has been a multiplicity of modernisms. What counts as modern science has been intensely competed over, and defined often in relation to classic physics.

BG: Artists' understanding of themselves as being contemporary is strong during modernity, and each generation it becomes stronger. Today, it is very intense, as most artists are interested in what is happening in different parts of the world, especially in the work of artists of the same generation. But at the same time they know - for reasons of artworld recognition, marketing, public attention, etc. - that they need to appear distinct from their contemporaries, so they use invented histories of other artists to demonstrate what it is that makes them different. For curators committed to internationalization, their distinctiveness is in the different historical narratives that they can propose and show to be present in the art that they choose to exhibit. Invented history, therefore, is absolutely primary in contemporary art: it is the most contemporary thing about it - more important than the influence of the market, more than an artist's individual brand within the symbolic economy. Or, you could say, within contemporaneity an artist or curator's invented history is his or her best brand.

AW: I am concerned that heterogeneity is becoming a bright new toy for art theory. There seems to be a widespread anxiety about sameness (a fear of hegemony). Yet the planet needs human behaviors that are commensurate with its needs. This bears on a whole host of issues, rights, and duties: reproduction, death, speech, communication, tool making, agitation, religion, and magic, just to list some. It leads us back to the matter of respect. Art history's current nightmare is part of a larger nightmare of relevance.

BG: Yes, but we must add that any idea of commensurability between humans has also to account for the tendency toward incommensurability revealed by, for example, the Holocaust.

TS: This is, perhaps, where coevality comes in: if there is an ethics particular to contemporaneity, it would be a practice that above all acknowledges and respects real, intractable difference, not just diversity; it would be antinomic, not humanist or generalist in some other way; it would require the creation of new equalities of coexistence - that is, contemporary kinds of commensurability - between the elements thrown up by a world shaped by insistent, ongoing, and seemingly fundamental incommensurability.

Well, having arrived at what is probably the core question about contemporaneity, we have run out of time to discuss it further. Perhaps, however, we have been doing so all along.

On behalf of my fellow conveners, I thank you all for your participation. It means a lot to me personally. I also believe that the questions we have raised are of significance for the profession, and beyond it.

\section{Public Conversation (Stone Hill Center)}

A brief introduction outlining the main themes of the workshop was given by TS. 
Audience Member: How do you think that your discussion will be viewed in the future? How do you think that you will be written into the history of art history?

CJ: We do have the anxiety of trying to find a role for art history in or against contemporaneity.

AW: Certainly we should pay attention to the evasions that follow from our politics, and admit them frankly.

DS: I remain optimistic. In Real Spaces I attempted to expand the ideas of art then prevalent. I see that a further effort needs to be made to relate them to contemporaneity. This is difficult to do, difficult to formulate in accessible ways. It is going to require a lot of constructive thought.

PG: The procedures for doing so are in place, and are not unusual. You propose a set of problems and questions, decide on which features to highlight, and for what purposes, then decide which allies to bring in to get to these goals. It will always be a competition with others over what we want to be - in this case, a competition over the definition of "contemporary."

AP: There is more writing about art than ever before - in art history departments, other parts of the academy, in blogs, etc. What is the role of professional art historians in this expanded discursive space? Some contemporary artists have approached this by adopting de-professionalizing modes. Art is being increasingly driven by experience, but it takes ever more extreme kinds of experience to capture attention. This is a direction in which art historians should not go.

Audience Member: What do you see as the differences between the roles of curators, critics and artists?

Thierry de Duve: In 2000 I curated an exhibition in Belgium with the title "Voici [Look]: 100 years of contemporary art." ${ }^{44}$ I showed works by Manet, Rodin, Fox Talbot, etc. right up to Dan Graham, along with new work and some commissions. The publicity statement read: "When a work speaks to you in the present tense, it is contemporary." These kinds of statements are always partial truths. I now think that I should have said: "A work of art remains our contemporary as long as it runs the risk of not being perceived as a work of art."

TS: A modernist answer, using avant-garde criteria, specifically a Duchampian one. It may be that this is reversed in contemporaneity, as the presumption now is that everything may act as art, be art. Actually, it will be more than simply reversed, as that starts the dialectic again. The question is spread over a wider range of terms - as Boris Groys explains.

AG: During the 1980s in Argentina, it was very dangerous to articulate the present. Since then, redefinition has become really important. I agree that some major change is occurring, but I do not think that we know its name as yet. I am not sure about "contemporaneity."

44 Thierry de Duve, Look: 100 Years of Contemporary Art (Ghent: Ludion, 2001). 
CJ: Another anxiety that the question raises is one about jobs for curators, critics, etc. Currently there is a match between graduates and jobs, but how long will this last? On the matter of the task before historians, critics, artists, etc., I would say that historians have the responsibility to locate an artwork historically, whereas the critic's primary task is to evaluate the work. Historians work in and through archives; we value thoroughness, however infinite an archive might be. Each practice requires a different research, teaching, learning context, with specialist knowledge needed for art, architecture, curatorship, etc. Doctorates for artists are raising many concerns. But category swapping is not new: Harald Szeemann treated curatorship as an art practice. ${ }^{45}$ "Ahistoricization" became favored during the postmodern moment. Curators such as Okwui reacted by a deep emphasis on actual history: events, documents, and works of art as historical instances. The increasing interest in the recent past is throwing up some interesting problems, for example, the re-performance of Performance Art.

AA: Interest in contemporary art is at an all-time high. $80 \%$ of applicants to graduate art history schools hope to study contemporary art; there is a huge interest among undergraduates; contemporary topics predominate at CAA. What is the source of this fascination?

TS: During the workshop many answers to this question came up. There are obvious, specific reasons: the buzz of high auction prices, the outrageous, publicity-grabbing behavior of some of the artists, the seemingly instant comprehensibility of much of the art, its fun aspect, its participatory forms, its fusion with new technologies and communicative networks. To me, however, the relevant answer is that contemporary art, when it is truly contemporary, offers responses to the conditions of contemporaneity, those in which we all live.

AW: While students are flocking to contemporary art, few of the art history institutions are following them: many departments, research institutes, and journals want to foster scholarship in other areas. Their thinking is something like this: perhaps the student who opts for Late Roman is the more independent thinker? Who is more likely to come up with the next paradigm shift in art historical thinking? Perhaps it will be a scholar of Chinese notation systems.

CJ: Actually, in China now many of those scholars also want to teach contemporary art and write about it. For art historians such as Wu Hung it has been liberating. Yet there is a more general concern: the Balkanization problems that have beset area studies in many disciplines have a particular resonance here. Given the expectation that the scholar of contemporary art have a global understanding, one that goes beyond art that is already internationalist, how do you acquire sufficient specialized knowledge to be accurate and effective in your understanding of art from specific regions?

AW: Scholars are motivated to do research and publish ideas that will act as interventions to help change the world for the better.

JS: Since the late 1960s, we expect that art will speak to its moment, in at least some way. Coming into this workshop I had felt that doing contemporary art history is the most

45 Hans-Joachim Müller, Harald Szeemann: Exhibition Maker (Ostfildern-Ruit and Maidstone: Hatje Cantz and Amalgamated Book Services, 2006). 
challenging kind that one could undertake. After Anne's earlier comment, I now feel that it might be easier than tackling art from an earlier period.

KM: One of the results of modernism having come to an end is that unidirectional presumptions of historical progression have evaporated. One consequence is that we no longer feel so separated from past periods. Premodern historical domains, especially, are more accessible than before (when we had to go through modernism to get to them). We inhabit "the end of time." [The froth in the present.]

Audience Member: What are artists saying that they do? How do they understand the contemporary?

AA: Actually, many of us teach in schools of art, many of our students are artists.

CJ: Many artists today are into knowledge production: it is their main material. For example, two artists who often work in Puerto Rico (Jennifer Allora and Guillermo Calzadilla) subtlety protested the environmental pollution coming from a US base on the island by carving the soles of sneakers with messages to that effect. Contemporaneity here is as important as it was to Gericault's Raft of the Medusa. Whenever they or others walked the beaches, that knowledge was spread. In contrast, there are some scholars, such as Whitney Davis, urging us to concentrate on the norm, the ordinary, the boring stuff produced throughout the history of art and artifacts.

AW: We need to be aware of the blindness of being in the present. "The contemporary" could turn out to be one of the great myths of our moment, our Orientalism, our Neoclassicism. Real Gericaults will appear when art meets lived experience. Truth might appear in the guise of history painting. Looking back people will say: when they used the term "contemporary" for good or ill, through their parapraxis, what were they disguising?

Audience Member: To me, everyone on this panel is an artist. Archives hold residues of the mind of the artist. As a sculptor I feel that writing about art should take on a more bottom-up, artist-oriented perspective. The theory party is over; it is time for intuition.

JS: We begin from what we cannot make sense of...

Audience Member: What about the patronage of contemporary art? Has it changed in character?

CJ: Artists can strive to manage their own agendas, many do so very carefully, including - after a certain point - choosing those who will be their patrons. But the more interesting point is that some artists strive to set the terms on which their art becomes contemporary: Bruce Nauman, for example.

TS: Yes, on this level, it is becoming obvious that there is a recent history to setting the agenda of what counts as contemporary art. If we take the idea of patronage in its broader sense (that of the patriarch, the "father" whose role is to both provide for and oversee the fortunes of the "family"), then we can say that, since the 1950s, agenda-setting in the artworld has been done, in turn, by artists, critics, theorists (in parallel, often, with arts administrators), gallerists, curators, auction houses and collectors. After last year's market implosion, it is not clear who will take up this role, or, indeed, if it will be taken up. To me, it is the art historian's turn to clarify what is contemporary art - in an open-ended, not an exclusionary or hegemonic, way, in full awareness that History is no longer setting our disciplinary agenda.

Audience Member: Is Jasper Johns a contemporary artist? 
TS: Not now, not for decades. He was a great innovator - along with many others, such as Rauschenberg, Oiticica, Beuys, Warhol, LeWitt - within late modern art. He was highly alert, as they were, to the contemporaneity within it. (And to his contemporaneity with it after all, he is the author of the painting from which he has taken a bite.)

Audience Member: Reading T.J. Clark's The Sight of Death leads me to ask: has the kind of time that has to be taken by a viewer of works of art changed in contemporary conditions? ${ }^{46}$

CJ: Jacques Derrida's Memoirs of the Blind would suggest that times and kinds of looking at art are not only subject to the conventions prevalent at any given time, but also that they can escape such determinations, and often do. ${ }^{47}$

TS: Contemporary art takes from its viewers some of the same times, but also offers many other different kinds of time: this is why, for instance, the installation has become so prevalent, and so varied as a format. At the same time, contemporary art is also giving back many and varied kinds of time. Encounter, exchange, participation - these are becoming increasingly evident. This is just one of the senses in which, I believe, contemporaneity is contemporary art's core subject, its main purpose, its definitive form.

46 T. J. Clark, The Sight of Death: An Experiment in Art Writing (New Haven: Yale University Press, 2006).

47 Jacques Derrida, Memoirs of the Blind: The Self-Portrait and Other Ruins (Chicago: University of Chicago Press, 1993). 


\section{(cc) EY-NG-ND}

This work is licensed under a Creative Commons Attribution-Noncommercial-No Derivative Works 3.0 United States License.

\section{ULIS D-Sork}

This journal is operated by the University Library System of the University of Pittsburgh as part of its D-Scribe Digital Publishing Program, and is co-sponsored by the University of Pittsburgh Press. 